\title{
Drug Delivery Systems Based on Polymeric Blend: A Review
}

\author{
Khalid Haneen Abass ${ }^{1}$, Ashraq Mohammed Kadim², Sara Kareem Mohammed ${ }^{3}$, Mohd Arif Agam ${ }^{4}$ \\ ${ }^{1}$ Department of Physics, College of Education for Pure Sciences, University of Babylon, Iraq. \\ ${ }^{2}$ Medical physics department, Hilla University College, Babylon, Iraq. \\ ${ }^{3}$ Technical Institute of Karbala, Iraq. \\ ${ }^{4}$ Department of Physics, Faculty of Applied Sciences and Technology, University Tun Hussein Onn Malaysia, 84600 Pagoh, Johor, \\ Malaysia.
}

\Corresponding authors. E-mail: pure.khalid.haneen@uobabylon.edu.iq, ishraq_mohammed@hilla-unc.edu.iq

Received: Jun. 14, 2021; Accepted: Oct. 18, 2021; Published: Dec.9, 2021

Citation: Khalid Haneen Abass, Ashraq Mohammed Kadim, Sara Kareem Mohammed, and Mohd Arif Agam, Drug Delivery Systems Based on Polymeric Blend: A Review. Nano Biomed. Eng., 202I, I3(4): 4I4-424.

DOI: $10.5101 /$ nbe.v13i4.p414-424.

\begin{abstract}
Non-idealistic pharmaceutical, pharmacokinetic and therapeutic-characteristic predominately combines to decrease the effectiveness of certain composites. For the vectoring of such compounds to target areas, and liposomes and nanoparticles carrier technology provides an interesting and intelligent approach to drug delivery. It provides drug delivery by conjugating the drug to a transporter particlelike, microscopes, liposomes, nanoparticles, et cetera. Due to their small size and other effective properties, microspheres are an important portion of a drug-particle delivery system. The release systems are very important and can compare with the fabrication methods, this when the drug delivery become inside the body. This review highlights different types of drug delivery and drug delivery methods this article also focuses on different types of microspheres such as radioactive float microspheres biological adhesive microspheres, polymeric microbes, microspheres, and magnetic microspheres.
\end{abstract}

Keywords: Types of drug delivery, Controlled release, Microspheres, Target drug delivery

\section{Introduction}

Since the beginning of the twentieth century, efficient drug delivery has been the subject of continuous study and search [1]. The evolution of modern delivery systems of the regulated releasing of drugs is one of the more interesting areas of search in pharmaceutical sciences [2]. Drug delivery concentrates on the most bioavailability at the strange post in the body [3]. The competence of a drug delivery system depends greatly on the choice of drug-carrying service [4].

Polymeric and Liposomes systems are currently the two common drug delivery systems [5]. The polymers are used in many applications after modifying the structure via mixing or blending fabrication [68]. Also, large molecules such as dendrites have an improved permeability and retention effect, which permit them to target cancer cells further effectively than smaller molecules [9]. Dendrimer as a drug delivery factor is considered a safe, a promising and selective drug delivery option dendrimer as a drug delivery system depends on the method that end nanoparticles to the body [10]. Liposomes have been explored, as carrier systems, more than any other system due to the presence of their various liposomes 
as delivery systems, which are characterized by carrying a variety of compounds in the primary section $[11,12]$. Early pioneers such as Berry and Gregoriades have established the idea that liposomes can infect drugs and can be used as drug delivery systems [13]. It is useful in stabilizing therapeutic compounds, [14]. Over the last decade, new drug delivery concepts have centered on Nano conductivity to improve release control and dose levels $[15,16]$. More recently, there has been an increasing interest in using micro-and Nano-fibers [17], for these microspheres can be used to control the release of hormones, antibiotics, vaccines, and medications [18].

Microsphere plays a substantial role in minimizing side effect and improve the bioavailability of conventional drugs [19]. Microspheres have several advantages over traditional drug delivery systems including being important or effective to administer effective therapeutic molecules in a controlled and sustained method to the target site while improving therapeutic effects [20, 21]. Microspheres have the possibility to be used for release and controlled/ extended of the drug, but the incorporation of mucus adhesive Property into microspheres will improve bioavailability and absorption of the drug [22-25]. Mucoadhesive microspheres enhance the close contact with the mucus strata, and drug targeting to the absorption location by anchoring bacterial adhesions [26] plant s lectin [27] antibodies [28] et cetera, it is used to retard or modify the drug-releasing [29]. Microspheres have the ability to deliver medication in a controlled manner [30]. Microspheres can be made from various natural and synthetic materials. Microspheres play an important turn in improving the bioavailability of traditional drugs and distorting side effects [31-35].

\section{Drug Delivery}

†Drug deliveries are the way or process of administering the pharmaceutical complex to fulfill the curative influence in humans being or animals. For a curative of human being ailments, nasal and pulmonary ways for drug delivery are gain rising import. This method supplies a promising alternative to injection medication delivery, particularly for protein and peptide therapeutics. For this objective. Many drug delivery systems have been developed and are being for investigated nasal \&pulmonary delivery [36-39]. This involves microspheres proliposomes, cyclodextrins, liposomes, gels, prodrugs, amongst others as shown in the figure below, Nanoparticles make up of biodegradable polymers display assurance in fulfilling the stringent requirements set on these delivery systems, like biocompatibility, stability against forces generated during aerosolization, ability to be transferred into an aerosol, biocompatibility, targeting of specific sites or cell populations in the lung, release of the drug in a predetermined manner, and degradation within an acceptable period as in Fig. 1 [40-42]. Some of the studies for drag delivery are listed in Table 1.

\section{Drug Delivery Routes}

Drugs might do inserted in to the human being body via different anatomic methods. Ther may do 1 dedicated for systemic influences or targeted to different members and ailments. A selection of the

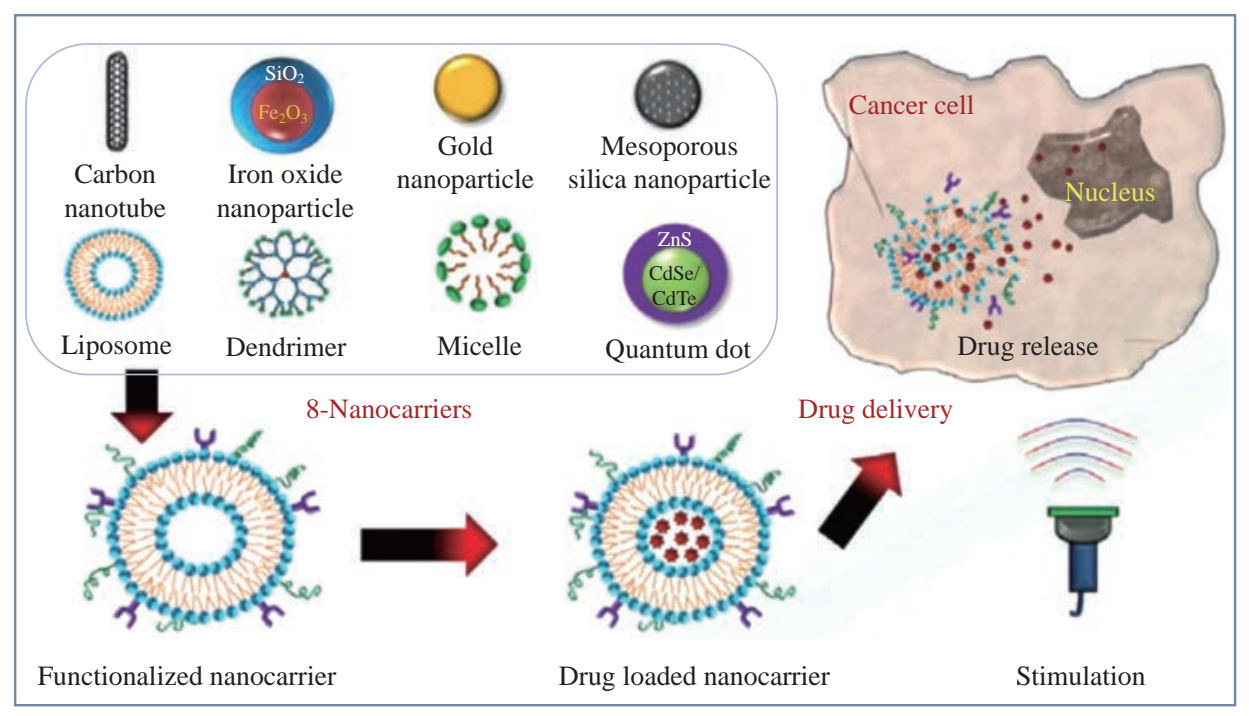

Fig. 1 Smart nanocarrier-based drug delivery systems for cancer therapy and toxicity studies [43]. 
Table 1 The survey of some researches for drug delivery

\begin{tabular}{|c|c|c|}
\hline & Researcher & Result \\
\hline 1 & $\begin{array}{l}\text { In 2003, } \\
\text { Galo et al. }\end{array}$ & $\begin{array}{l}\text { Microspheres were prepared from poly (vinyl alcohol) and methacrylate using ultrasound-assisted cross- } \\
\text { linking reaction. These microspheres used as versatile biomaterial for potential biomedical appli-cation. They } \\
\text { showed feasibility of synthetic and met-hodology approaches for the obtainment of microde-vices suitable } \\
\text { for regulated drug delivery and as contrast agent for aerographic. }\end{array}$ \\
\hline 2 & $\begin{array}{c}\text { In 2009, } \\
\text { Piush Khare } \\
\text { and Sanjay K. Jain }\end{array}$ & $\begin{array}{l}\text { Prepared chitosan microspheres and studied the effect of viscosity of external oil phase on the properties } \\
\text { of microspheres prepared by emulsification method. Effect of viscosity on percent mucoadhesion, percent } \\
\text { drug entrapment, zeta potential, and percent process yield of microspheres has been observed. The results } \\
\text { revealed a difference in the drug release pattern of the different microspheres prepared as a function of } \\
\text { viscosity of different oil phase. Use of low viscose oil resulted in the formulation of spherical and small size } \\
\text { microspheres. }\end{array}$ \\
\hline 3 & $\begin{array}{l}\text { In } 2012 \text {, } \\
\text { M.N. Abdorrwza, } \\
\text { et al. }\end{array}$ & $\begin{array}{l}\text { Studies the effects of acid hydrolysis on physicoch-emical and rheological properties of sago starch } \\
\text { investigated. Sago starch hydrolyzed in hydrochloric acid. The molecular weight distribution, physicoch- } \\
\text { emical, thermal, and rheological properties of acid-hydrolyzed sago starch (AHS) were determined. The } \\
\text { results showed both amylose and amylopectin were hydrolyzed and depolymerised to a different extent. By } \\
\text { controlling the degree of hydrolysis, the amylose content can be increased; this improves the gel strength and } \\
\text { consequently utility for products that need high amylose content such as films. Acid hydrolysis can decrease } \\
\text { the gelling point and therefore improve the solubility in water }\end{array}$ \\
\hline 4 & $\begin{array}{c}\text { In2014, } \\
\text { Geng, } \\
\text { Shengyong, et al. }\end{array}$ & $\begin{array}{l}\text { Two kinds of doxorubicin-loaded liposomes incorpo-rated with cholesterol derivatives were studied. Both } \\
\text { showed better long-term storage stability than the conventional PC-liposome due to cholesterol unit. After } \\
\text { PEGylation, their spontaneous drug leakages both in PBS and 50\% serum were inhibited, and the storage } \\
\text { stability was improved. The in vivo study showed that PEGylation could increase the plasma concentration } \\
\text { and the area under the plasma concent-ration vs. time curve (AUC) of DOX, and the half-life was more } \\
\text { prolonged than the non-PEGylated ones. In particular, the neutral cholesterol derivative ACB prolonged the } \\
\text { circulation time of liposomes in systemic circulation and improved drug }\end{array}$ \\
\hline
\end{tabular}

prepared novel starch-poly(vinyl alcohol) micropar-ticles , polymer-coated drug microparticles were prepared by emulsion method. OM, SEM, and AFM study revealed that the microparticles were within $10 \mu \mathrm{m}$ of size Helen et al. with smooth spherical shape. FTIR showed absence of drug polymer interaction. Hence this novel polymer of starch and poly(vinyl alcohol) can be utilized for control release of the drug from a targeted delivery device

Electrospun poly( $\varepsilon$-caprolactone) (PCL) microfibers loaded with poly(3,4-ethylenedioxythiophene) nanoparticles (PEDOT NPs) and curcumin with diameter of $3.9 \pm 0.7 \mu \mathrm{m}$ have been prepared. PEDOT NPs,

which are mainly located inside the PCL microfibers, exhibit a diameter of $99 \pm 21 \mathrm{~nm}$. PEDOT- and

In 2018,

6 Puiggalí-Jou, Anna, et al.

In 2018,

7 Gholam Reza Mahdavinia et al. curcumin-containing PCL microfibers behave as extracellular cell matrices, facilitating cell spreading and enhancing cell proliferation because of their heterogeneity and roughness. The release of curcu-min from the PCL microfibers by simple diffusion is very slow, external electric stimuli being required to boost and regulate the curcumin delivery process. PEDOT NPs behave as electroactuators upon applic-ation of welldefined potential pulses, increasing their diameter by about $17 \%$ and migrating from inside the PCL matrix to the surface of the micro-fibers. This electromechanical actuation mechanism affects the structure of the PCL matrix, promoting the release of curcumin that increases with the number of pulses

Manufactured magnetic chitosan/PVA/laponite RD beads utilized for adsorption study of a model pro-tein, bovine serum albumin (BSA). The adsorption of BSA on beads was $\mathrm{pH}$ - dependent where smaller mass of protein adsorbed at $\mathrm{pH}$ values lower than isoelectric point of BSA. The results showed that magnetic laponite RD can improve the adsorption capacity of magnetic beads for BSA in which hydr-ogel with the highest content of magnetic laponite RD demonstrated the maximum adsorption capacity for BSA (qm = $240.5 \mathrm{mg} / \mathrm{g}$ )

It has been shown that PAMAM can enhance aque-ous solubility, stability, solubility, drug release, targeting and pharmacokinetics of different drugs. The future of drug delivery will be the manufacture of "nanobots" capable of performing multiple func-tions within the body. These "nanorobots" can either be degradable or leave the body through excretory methods. Designing a sophisticated drug delivery platform requires a multidisciplinary approach that includes the disciplines of chemistry, engineering, and pharmacy.

In 2018, Chauhan, A. S. Dendrimer's nanotechnology has the potential to create next-generation drug delivery platforms due to its multifunctional capability. The future of the divers will be to exploit their multif-unctional capabilities and engineered platforms. The idea that originated through "tree branches" has now taken root in "drug delivery".

Drug delivery devices are promising tools in the pharmaceutical field, as they are able to maximize the therapeutic effects of the delivered drug while minimizing the undesired side effects. In the past years, electrospun nanofibers attracted rising attention due to their unique features, like biocompatibility and broad In 2021, flexibility. Incorporation of active principles in nanofibrous meshes proved to be an efficient method for in 9 A. Luraghi, et al. situ delivery of a wide range of drugs, expanding the possibility and applicability of those devices. The principle of electrospinning and different fields of applications are treated to give an overview of the recent literature, underlining the easy tuning and endless combination of this technique, that in the future could be the new frontier of personalized medicine.

The microspheres were produced with diameters up to 150 micrometers and diameter keep stable in size with narrow size distribution for the high concent-ration of PVA. The wall thickness increased with increasing the In 2019, concentration of PVA. The static stability of low concentration is low and incipient but it is moderate at the while the moderate concentration and high indicates acceptable stability. 
method of administration be based on an ailment, and the product available, and the influence required drugs may be administered straightway to the member influenced by disease or given systemically and targeted to the diseased member. Classification of various methods of systemic medication delivery by an anatomical method is shown in Table 2 [54-57], while Table 3 represents the microspheres prepared from polymers.

Table 2 A classification of various anatomical routes for systemic drug delivery [57]

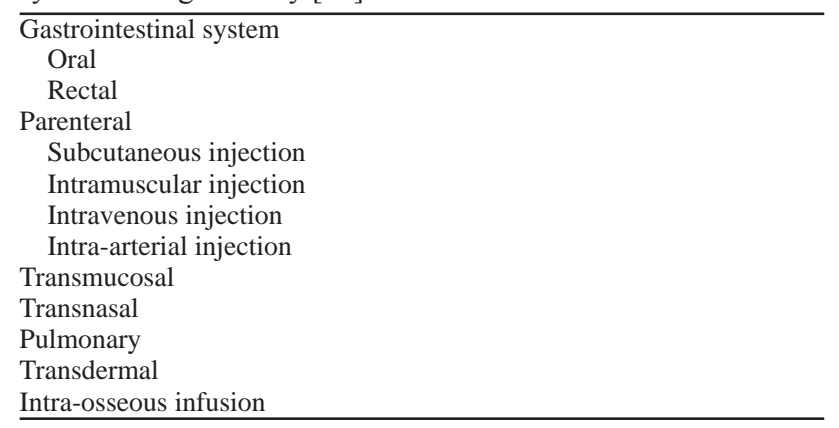

\section{Drug Delivery Types}

Drug delivery systems have many systems such as listed in Table 4.

\section{Microsphere}

Microspheres are teeny spheres particles that have diameters ideal ( 1 to $1000 \mu \mathrm{m})$ and are sometimes called for (microparticles) [68]. There are two types of micro matrices, microspheres\& microcapsoles (Fig. 2), which are characterization as microcapsules are these in which the entrapped material is clearly enclosed by a characteristic capsule wall and micro matrices as the entrained is dispersed throughout the matrix [69].

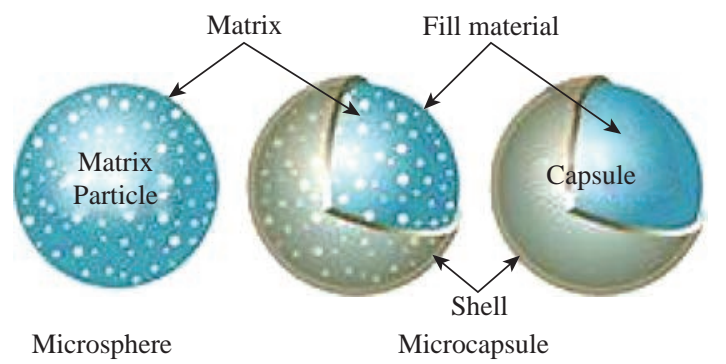

Fig. 2 Microspheres and microcapsules [70].

Microspheres can be produced from different synthetic \&natural materials. Mineral and vitreous microspheres, polymer, and ceramic are commercially available [71]. Microspheres found as solid or hollow [72]. It has a wide range of various applications in past years as shown in (Fig. 3), which shows the extent to which researchers expect the development and use of the microspheres in wider and more applications in the coming years due to its practical \& scientific importance [73].

Table 3 Polymers used in microspheres [58-63]

\begin{tabular}{cc}
\hline Polymer & Mechanism \\
\hline Modified starch, HPMC, Carbopol 974P & Slower release of drug \\
Ethyl Cellulose & Controlled release for longer period of time. \\
PLGA, Chitosan & Vaccine delivery. \\
PLA, PLGA, Starchcyanoacrylate etc(PEG-) liposomes & Drug delivery without toxic side effects \\
Magnetic polystyrene microspheres & Specific cell labelling \\
Polymer resins such as Agarosepolyacroline, sephadex & Affinity chromatography \\
Chitosan coated PlGA microspheres & Targeted drug delivery \\
Polyvinyl alcohol, polyacrylamide & Adsorption of harmful substances in blood \\
\hline
\end{tabular}

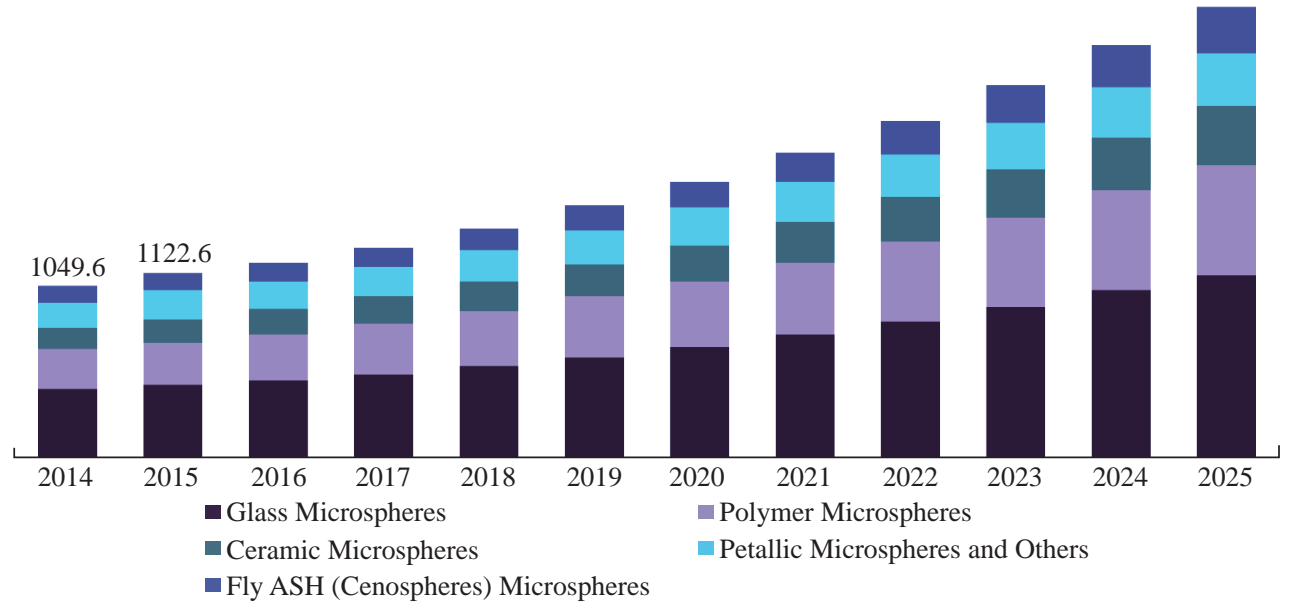

Fig. 3 Timeline of the evolution of microspheres in the coming years [74]. 
1. Liposomes

Are made of phospholipids, they may or may not contain cholesterol. Phospholipids have two hydrophobic tails [64].

\section{Spheres}

Microspheres are tiny spheres particles that have diameters typically (1 into $1000 \mu \mathrm{m})$, and sometimes called (micro particles) [65].

3. Fibers

Fibers it's known as "fibers to diameters least than 100 nanometers [66].

4. Dendrimers

Are the emerging polymeric architectures that are known for their defined structures, Versatility in drug delivery and high functionality whose property is similar to with biomolecules [67].
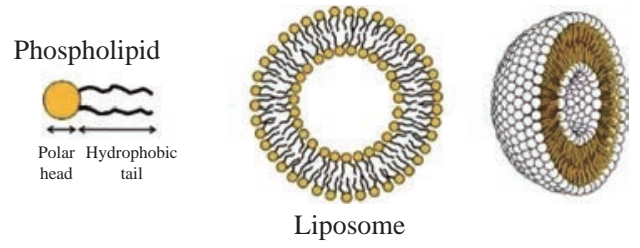

Sizes: 10 's nm to submicrometer

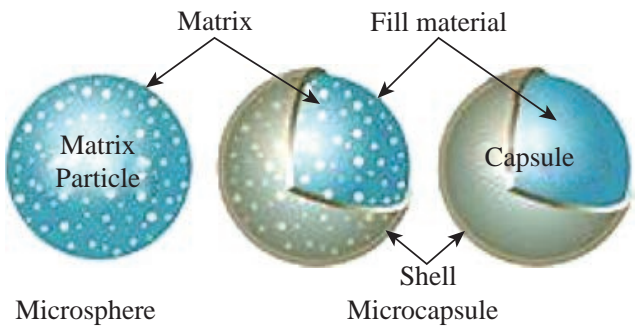

Microsphere

Microcapsule

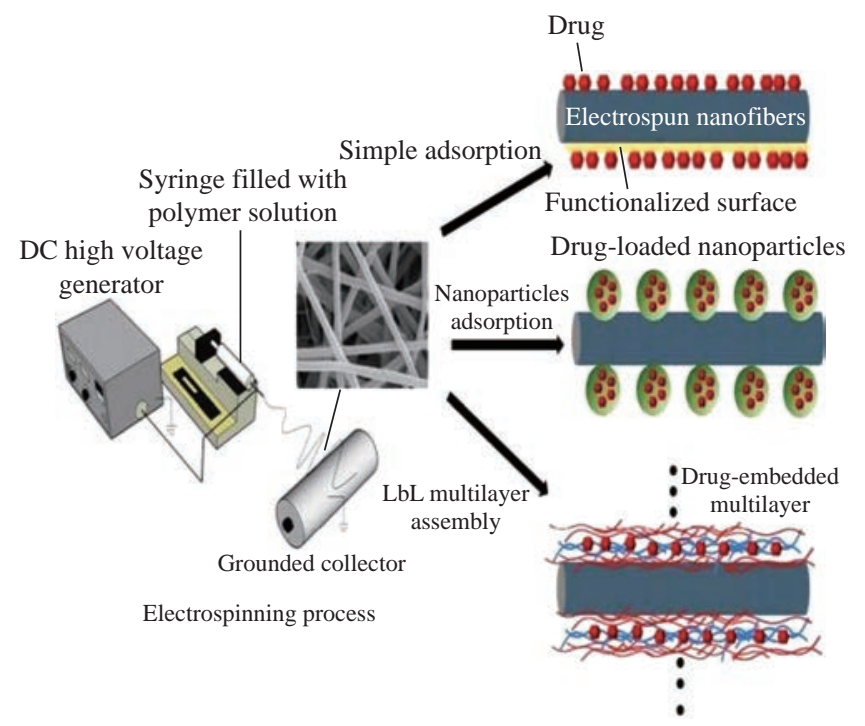

The Construction of D endrimers-1

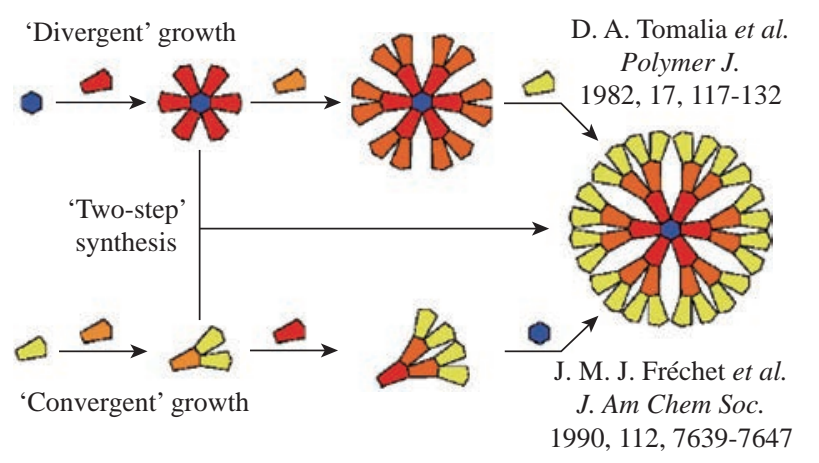

\section{Types of Microspheres Bioadhesive microspheres}

Bioadhesive Microspheres those types from microspheres globes show long lodging time in the application location and reason intimate contact with a location of absorption \& produce better curative action $[75,76]$.

\section{Magnetic microspheres}

Magnetic microspheres are molecules above molecule the tiny sufficient to Rotation through capillaries without producing occlusive occlusion $(<4 \mu \mathrm{m})$ but are acceptable enough microscopy: as holders used for the new drug delivery system (magnetic Ferro) as they are captured in microvessels and withdrawn. To adjacent tissues by magnetic field 0.5-0.8 Tesla [77- 79].

\section{Floating microspheres}

Intestinal floating microscopic balls are low intensity systems that have sufficient buoyancy to bypass stomach contents and remain in the stomach for a long 
time without affecting the rate of gastric emptying. The drug is released slowly at the required rate [80].

\section{Radioactive microspheres}

Deliver height ray dose into the targeted zones without harmful to natural surrounding tissues. There are injected into arteries that direction to tumors. The unlike types of radioactive microspheres are $\{\alpha\}$ emitters, $\{\beta\}$ emitters, and $\{\gamma\}$ emitters $[81,82]$.

\section{Polymeric microspheres}

Biodegradable polymeric microspheres are those include biodegradable polymers that protract a lodging time while contact with snotty membrane because of its rise property grade of swelling with a watery middle, resultant from gel formation. The average and reach of drug reals are controlled by the focus of polymer and the release pattern in a continuous way. Artificial polymeric microspheres are those which are made up of artificial polymers and are used as a bulking agent, fillers, embolic particles, drug delivery composites et cetera [82, 83].

\section{Advances in Mixed Polymer-based Materials for Sustainable Drug Release}

Micro and Nanomaterials capable of encapsulating pharmaceutical factors have been exploration as treatment vectors for achieving long-term drug administration [5, 84] and best control. Even now, a major majority of carriers are depending on dendrites, [85] liposomes, [86] organic polymers [87] and inorganic molecules [88]. In that area, it lately characterization a generic way for encapsulating desired types to Nano-cohesive polymer particles [89 by coordinate polymerization followed by rapid precipitation, [90, 91] whose utility has been demonstrated by confining organic dyes. Magnetic nanoparticles and quantum dots within blue fluorescent domains (hereinafter indicate to as $\mathrm{Zn}$ (bix) that are produced by binding to $\mathrm{Zn}^{2+}$ mineral ion during of 1,4bis (imidazole-1-ylmethyl) benzene (bix) with bonds Organic. Due to their little bulk and ability to trap a wide range of materials, we think that coordinated Nano polymers also provide a pledge of drug encapsulation and thus new functional carriers for drug delivery.

Until now, some procedures have been made in using mineral- organic frame (MOFs) as drug delivery systems as in Fig. 4 [92- 95].

Fig. 5 represent the SEM pictures of the dentin surface and the morphology of the longitudinal

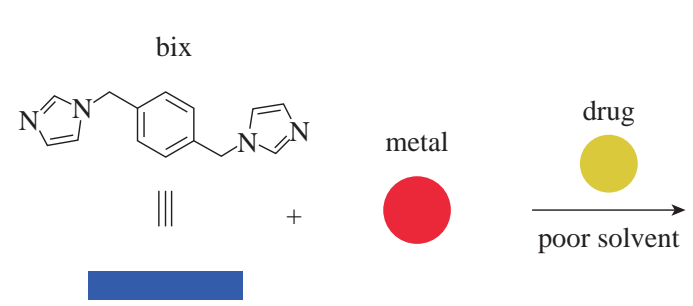

(a)

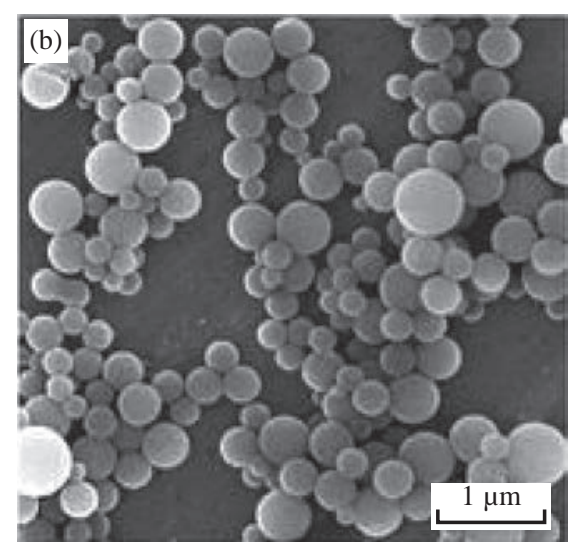

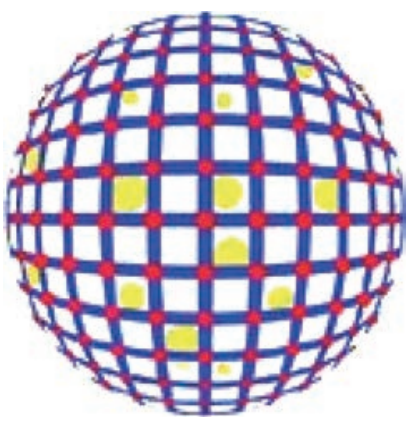

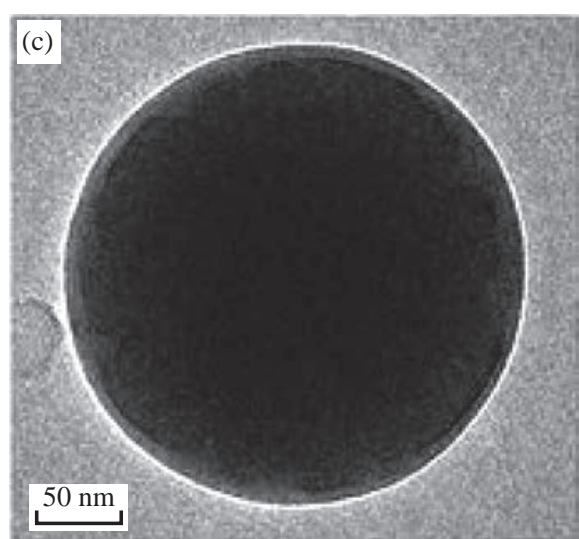

Fig. 4 (a) Schematic diagram describing the encapsulation of drugs in mineral and organic domains created by the connection of metal ions, such as $\mathrm{Zn}^{2+}$, through multi-element organic bonds, such as bix. (b) SEM and (c) TEM images of a representative colloidal solution of DOX / Zn (bix) domains [96]. 

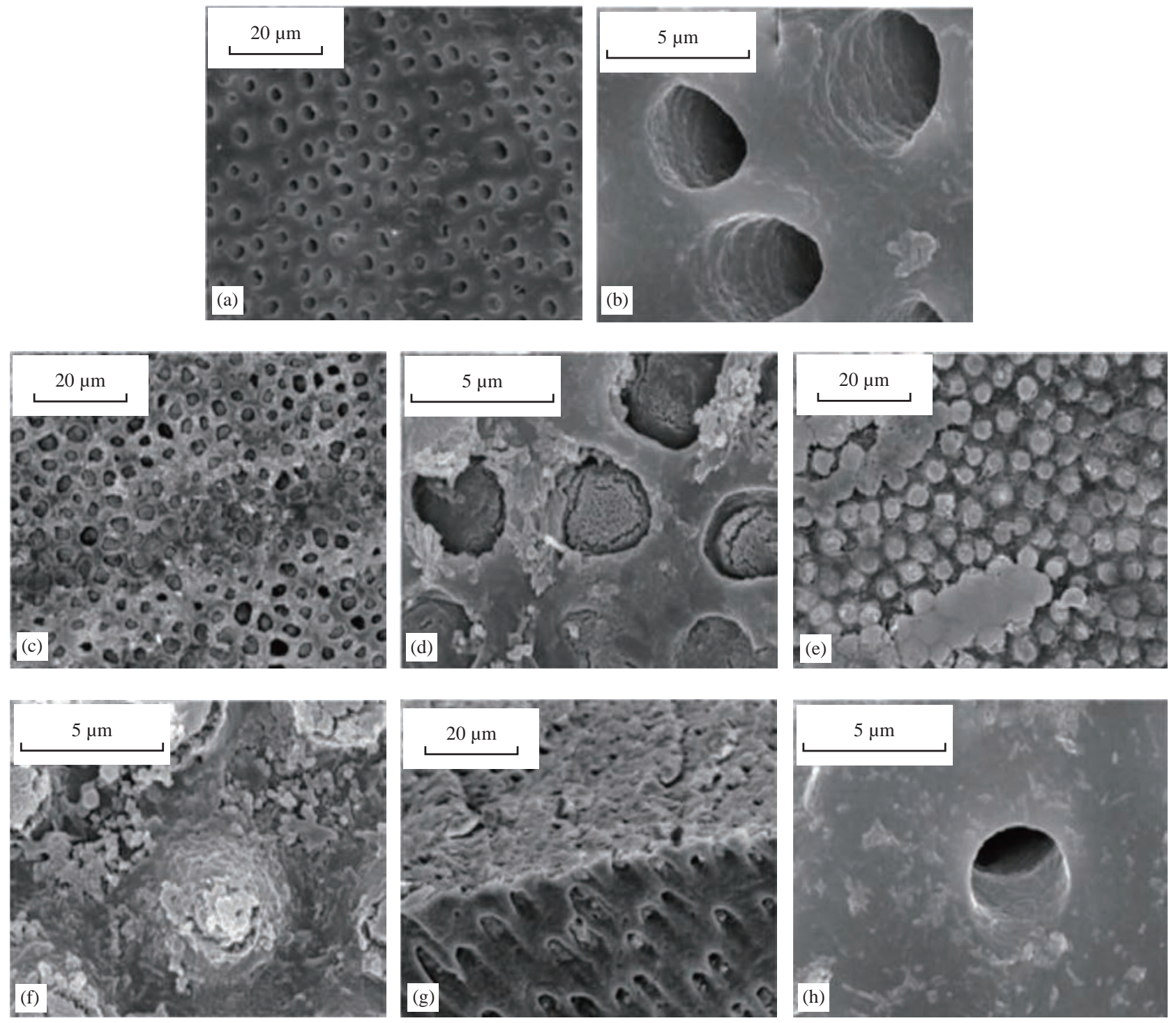

Fig. 5 SEM pictures of the dentin surface and the morphology of the longitudinal segment indicating dentin tubular occlusion, (a) and (b) The dentin disc etched with 10\% citric acid. (c) and (d) The dentin tubes covered with freshly formed rod-like. (e) and (f) The dentin tubes are covered with newly created sediment. (g) Dentin tubes are blocked from the dentin surface. (h) In the control set [97].

segment indicating dentin tubular occlusion, where (A, B) the dentin disc etched with $10 \%$ citric acid lent for 30 a second every dentin tubes have been opened. (C, D) The dentin tubes are covered with freshly formed rod-like crystals after the dentin discs are coated with PAMAM dendrites and submerged in SBF for 1 watt. The outer part of the tubes left a patent. (E, F) The dentin tubes are covered with newly created sediment showing the surface shape of dentin. Part of the surface of the dentin was covered with spherical and bar-like crystals. (G) Dentin tubes are blocked from the dentin surface to a deepness of about $20 \mu \mathrm{m}$. (H) In the control set, no significant variation was observed before and after of immersion of the dentinal discs directly in SBF for one week, without treatment [97].
Fig. 6 shows SEM images for re-mineralization of demineralized dentin disc. Fig. 6(a) and (b) demineralized dentine tablets for $72 \mathrm{~h}$ with neuter EDTA solution. Fig. 6(c) and (d) EDTA demineralized ivory tablets intertwined with G3.0 (PAMAM) bushes, showing a "corn on cob" appearance, with 0.25 percent glutaraldehyde for 24 h. Fig. 6(e) and (f) show that after treating PAMAM interlocking dentin discs with SBF for 1 watt, peel-like crystals were induced on the surface and covered the wall of the dentin tubules, with the remaining dentin tubules remaining from the patent. (Insert (e)) EDS showed that the molar ratio of $\mathrm{Ca} / \mathrm{P}$ for mineral crystals was $1.59 \pm 0.05$. (G, $\mathrm{H})$ No significant mineral crystals were formed on demineralized dentin discs after $1 \mathrm{~W}$ SBF immersion, without treatment of PAMAM dendrites [97]. 

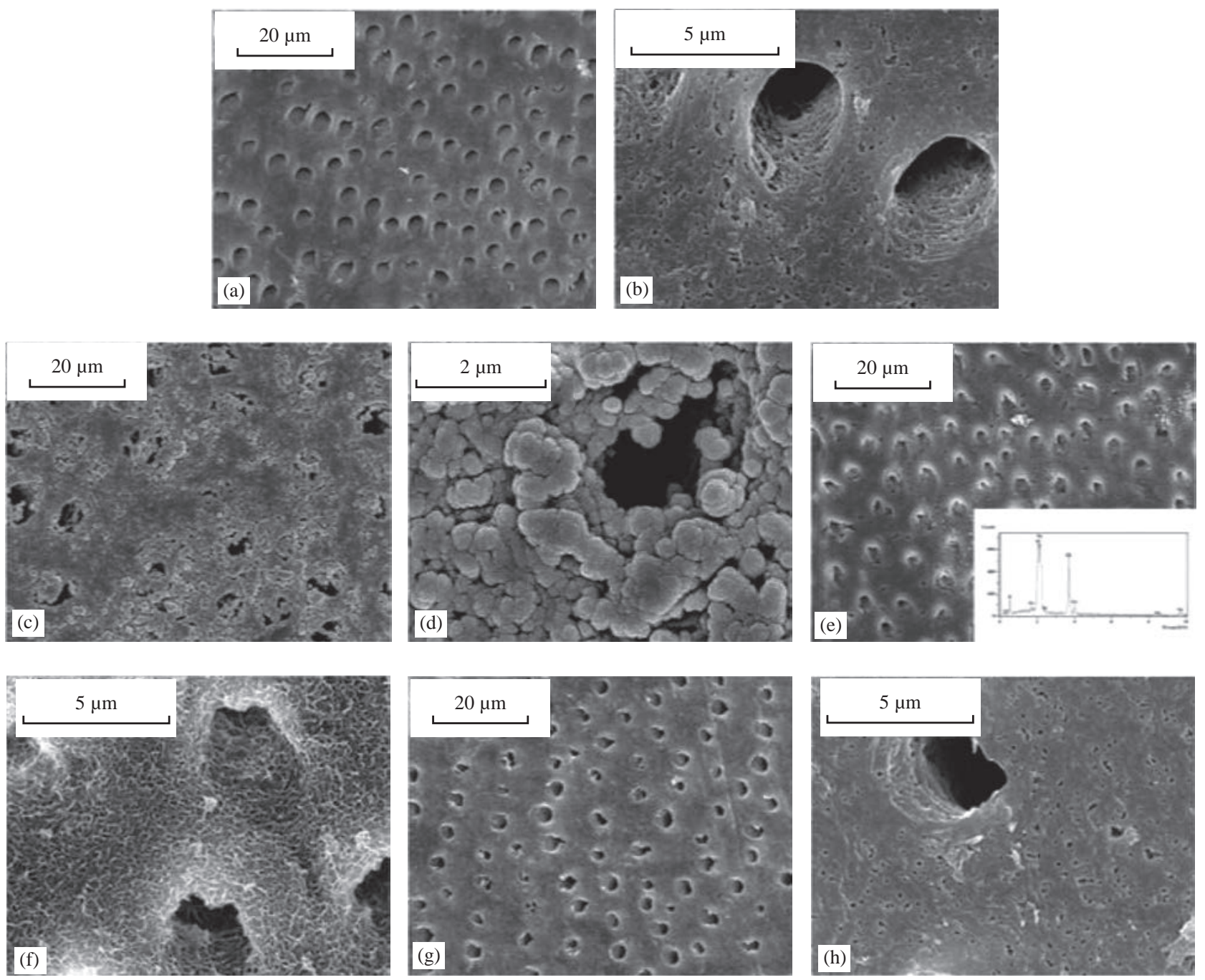

Fig. 6 SEM images of re-mineralization of demineralized dentin disc. (a) and (b) Demineralized dentine tablets for $72 \mathrm{~h}$ with neuter EDTA solution. (c) and (d) EDTA demineralized ivory tablets intertwined with G3.0 (PAMAM) bushes. (e) and (f) After treating PAMAM interlocking dentin discs with SBF for 1 watt. (g) and (h) No significant mineral crystals [97].

\section{Conclusions}

Through this article, methods of drug delivery have been clarified new drug delivery systems have received increased attention in recent years. Nasal and lung routes are going the importance of increasing drug delivery, therefore, the smaller microspheres represent better way of fabrication. Medicines are given directly or $\uparrow$ systemically to the affected organ. The most prominent properties of nanoparticles arise due to their biocompatibility and decomposition within an acceptable period of time, for this, the microspheres must dissolving with the human environment. Drug delivery systems have a very vast range of applications and potentially have a spectacular future.

\section{Conflict of Interests}

The authors declare that no competing interest exists.

\section{References}

[1] S. Mitra, U. Gaur, P.C. Ghosh, et al., Tumour Targeted Delivery of Encapsulated Dextran-Doxorubicin Conjugate Using Chitosan Nanoparticles as Carrier. J ournal of Controlled Release, 2001, 74(1-3): 317-323.

[2] Y.W. Chein, Oral Drug Delivery and Delivery Systems. Novel D rug D elivery Systems, 1992, 50: 139-177.

[3] A. Mitra, B. Dey, Chitosan Microspheres in Novel Drug Deliver Systems. Indian J ournal of Pharmaceutical Sciences, 2011, 73(4): 355.

[4] F. Sharifi, A.C. Sooriyarachchi, H. Altural, et al., Fiber Based Approaches as Medicine Delivery Systems. ACS Biomaterials Science \& Engineering, 2016, 2(9): 14111431.

[5] R. Langer, Drug Delivery and Targeting. Nature, 1998, 392(6679 Suppl): 5-10.

[6] A.N. Al-Jamal, Q.M. Hadi, F.J. Hamood, et al., Particle Size Effect of Sn on Structure and Optical Properties of PVA-PEG Blend. Proceedings - International C onference on Developments in eSystems Engineering, DeSE, 2019: 736-740.

[7] S.M. Al Asadi, F.J. Hamood, K.H. Abass, et al., The Effect of MgO Nanoparticles on Structure and Optical Properties 
of PVA-PAAm Blend. Research J ournal of Pharmacy and Technology, 2019, 12(6): 2768-2771.

[8] K.S. Sharba, A.S. Alkelaby, M.D. Sakhil, et al., Enhancement of Urbach Energy and Dispersion Parameters of Polyvinyl Alcohol with Kaolin Additive. NeuroQuantology, 2020, 18(3): 66-73.

[9] H. Maeda, J. Fang, T. Inutsuka, et al., Vascular Permeability Enhancement in Solid Tumor: Various Factors, Mechanisms Involved and its Implications. International Immunopharmacology, 2003, 3(3): 319-328.

[10] I. Mishra, Dendrimer: a Novel Drug Delivery System. J ournal of Drug Delivery and Therapeutics, 2011, 1(2).

[11] A.D. Bangham, M.M. Standish, J.C. Watkins, Diffusion of Univalent Ions Across the lamellae of Swollen Phospholipids. Journal of Molecular Biology, 1965, 13(1): 238-252.

[12] T.M. Allen, P.R. Cullis, Liposomal Drug Delivery Systems: from Concept to Clinical Applications. Advanced drug delivery reviews, 2013, 65(1): 36-48.

[13] G. Gregoriadis, Y. Perrie, Liposomes, Encycl Life Sci, 2010: 1-8.

[14] L. Sercombe, T. Veerati, F. Moheimani, et al., Advances and Challenges of Liposome Assisted Drug Delivery. F rontiers in P harmacology, 2015, 6: 286.

[15] E. Blanco, C.W. Kessinger, B.D. Sumer, et al., Multifunctional Micellar Nanomedicine for Cancer Therapy. Experimental biology and medicine, 2009, 234(2): 123-131.

[16] S. Vijayaraghavalu, D. Raghavan, V. Labhasetwar, Nanoparticles for Delivery of Chemotherapeutic Agents to Tumors. Current opinion in investigational drugs (London, England: 2000), (2007), 8(6): 477-484.

[17] A. Senthil, V.B. Narayanaswamy, I. Ajit, et al., Mucoadhesive Microspheres. International J ournal of Research in Ayurveda and Pharmacy, 2011, 2(1): 55-59.

[18] N.R. Kadam, V. Suvarna, Microsphere: a Brief Review. Asian Journal of Biomedical and Pharmaceutical Sciences, 2015, 5(47): 13.

[19] S. B.Gholap, S.K. Banarjee, D.D. Gaikwad, et al., Hollow microsphere: A Review. International J ournal of Pharmaceutical Sciences Review and Research, 2010, 1(1): 74-79.

[20] K.H. Ramteke, V.B. Jadhav, S.N. Dhole, Microspheres: as Carrieres used for Novel Drug Delivery System. Iosrphr, 2012, 2(4): 44-48.

[21] K. Sahil, M. Akanksha, S. Premjeet, et al., Microsphere: A Review. Int. J. Res. Pharm. Chem, 2011, 1(4): 11841198.

[22] J. Kunisawa, A. Okudaira, Y. Tsutusmi, et al., Characterization of Mucoadhesive Microspheres for the Induction of Mucosal and Systemic Immune Responses. Vaccine, 2000, 19(4-5): 589-594.

[23] K.P.R. Chowdary, Y.S. Rao, Mucoadhesive Microspheres for Controlled Drug Delivery. Biological and Pharmaceutical Bulletin, 2004, 27(11): 1717-1724.

[24] V. Belgamwar, V. Shah, S.J. Surana, Formulation and Evaluation of Oral Mucoadhesive Multiparticulate System Containing Metoprolol Tartarate: an in Vitro-ex Vivo Characterization. Current Drug Delivery, 2009, 6(1): 113121.

[25] N. Özdemir, S. Ordu, Y. Özkan, Studies of Floating Dosage forms of Furosemide: in Vitro and in Vivo Evaluations of Bilayer Tablet Formulations. Drug Development and Industrial Pharmacy, 2000, 26(8): 857866.

[26] K.M.Z. Hossain, U. Patel, I. Ahmed Development of Microspheres for Biomedical Applications: a Review. Progress in biomaterials, 2015, 4(1): 1-19.

[27] C.M. Lehr, J.A. Bouwstra, W. Kok, Bioadhesion by Means of Specific Binding of Tomato Lectin.
Pharmaceutical Research, 1992, 9(4): 547-553.

[28] S. Wright, L. Huang, Antibody-Directed Liposomes as Drug-Delivery Vehicles. Advanced Drug Delivery Reviews, 1989, 3(3): 343-389.

[29] P.R. Radhika, M. Luqman, C.H. Borkhataria, Preparation and Evaluation of Delayed Release Aceclofenac Microspheres. Asian J ournal of Pharmaceutics (AJP): F ree full text articles from Asian J Pharm, 2014, 2(4).

[30] P.N. Bhangale, H.S. Mahajan, R.D. Wagh, Formulation and Development of Sustained Release Microspheres of Metformin Hydrochloride. Research J ournal of P harmacy and Technology, 2010, 3(1): 267-271.

[31] S.P. Senthil, K.L. Senthilkumar, Preparation and In-Vitro Evaluation of Abacavir Sulphate Loaded Microspheres Cross-Linked by Different Concentrations of Glutaraldehyde. Research J ournal of Pharmacy and Technology 2010, 3.4: 1128-1131.

[32] M. Jamini, S.A. Rawat, Review on Microsphere. Res. J . Pharm. B oil. Chem. Sci, 2013, 4(1): 1223-1233.

[33] N.R. Patel, D.A. Patel, P.D. Bharadia, et al., Microsphere as a Novel Drug Delivery. International Journal of Pharmacy Life Sciences, 2011, 2(8).

[34] S.H. Kareem, A.M. Naji, Z.J. Taqi, et al., Polyvinylpyrrolidone Loaded-MnZnFe ${ }_{2} \mathrm{O}_{4}$ Magnetic Nanocomposites Induce Apoptosis in Cancer Cells Through Mitochondrial Damage and P53 Pathway. J ournal of Inorganic and Organometallic Polymers and M aterials, 2020, 30(12): 5009-5023.

[35] K.H. Abass, A.H. Hamed, Reduction of Energy Gap in $\mathrm{ZrO}_{2}$ Nanoparticles on Structural and Optical Properties of Casted PVA-PAAm Blend. J ournal of Green Engineering, 2020, 10(7): 4166-4176.

[36] J.K. Patra, G. Das, L.F. Fraceto, et al., Nano based drug delivery systems: recent developments and future prospects. J ournal of Nanobiotechnology, 2018, 16(1): 71.

[37] G. Tiwari, R. Tiwari, B. Sriwastawa, et al., Drug Delivery Systems: An Apdated Review. International J ournal of Pharmaceutical Investigation, 2012, 2(1): 2.

[38] A.J. Guastella, I.B. Hickie, M.M. McGuinness, et al., Recommendations for the Standardisation of Oxytocin Nasal Administration and Guidelines for its Reporting in Human Research. Psychoneuroendocrinology, 2013, 38(5): 612-625.

[39] C.V. Pardeshi, V.S. Belgamwar, Direct Nose to Brain Drug Delivery Via Integrated Nerve Pathways Bypassing the Blood-Brain Barrier: an Excellent Platform for Brain Targeting. Expert Opinion on D rug Delivery, 2013,10(7): 957-972.

[40] A. Boxi, Preparation and Characterization of Gelatin Stavudine Conjugated Liposomal Nanoparticles For Better Delivery in Case of Hiv. Doctoral Dissertation, National Institute Of Technology Rourkela, 2015.

[41] S. Maiti, K.K. Sen, (Eds.). Bio-Targets and Drug Delivery Approaches. CRC Press, 2016.

[42] G. Tiwari, R. Tiwari, B. Sriwastawa, et al., Drug Delivery Systems: An Updated Review. International J ournal of Pharmaceutical Investigation, 2012, 2(1): 2.

[43] S. Hossen, M.K. Hossain, M.K. Basher, Smart Nanocarrier-Based Drug Delivery Systems for Cancer Therapy and Toxicity Studies: A Review. J ournal of Advanced Research, 2019,15: 1-18.

[44] G. Paradossi, F. Cavalieri, E. Chiessi, et al., Poly(Vinyl Alcohol) as Versatile Biomaterial for Potential Biomedical Applications. J ournal of Materials Science: Materials in Medicine, 2003, 14(8): 687-691.

[45] P. Khare, S.K. Jain, Influence of Rheology of Dispersion Media in the Preparation of Polymeric Microspheres Through Emulsification Method. AAPS Pharm Sci Tech, 2009, 10(4): 1295-1300 
[46] M.N. Abdorreza, M. Robal, L.H. Cheng, et al., Physicochemical, Thermal, and Rheological Properties of Acid-Hydrolyzed Sago (Metroxylon Sagu) Starch. LWTF ood Science and Technology, 2012, 46(1): 135-141.

[47] S. Geng, B. Yang, G. Wang, et al., Two Cholesterol Derivative-Based PEGylated Liposomes as Drug Delivery system, Study on Pharmacokinetics and Drug Delivery to Retina. Nanotechnology, 2014, 25(27): 275103.

[48] H. Chattopadhyay, A.K. De, S. Datta, Novel Starch-PVA Polymer for Microparticle Preparation and Optimization Using Factorial Design Study. International Scholarly Research Notices, 2015: 2015.

[49] A. Puiggalí-Jou, A. Cejudo, L.J. del Valle, et al., Smart Drug Delivery from Electrospun Fibers through electroresponsive polymeric nanoparticles. ACS Applied Bio M aterials, (2018), 1(5): 1594-1605.

[50] G.R. Mahdavinia, M. Soleymani, H. Etemadi, et al., Model Protein BSA Adsorption Onto Novel Magnetic Chitosan/PVA/Laponite RD Hydrogel Nanocomposite Beads. International journal of Biological Macromolecules, 2018, 107: 719-729.

[51] A.S. Chauhan, Dendrimers for drug delivery. M olecules, 2018, 23(4): 938.

[52] A. Luraghi, F. Peri, L. Moroni, Electrospinning for drug delivery applications: A review. J ournal of Controlled release, 2021, 334: 463-484.

[53] N. Hadi, A. Braihi, S.K. Mohammed, Effect of Flow Behavior on the Production of PVA/Dextrin Microspheres. International J ournal of Engineering and Technology, 2019, 8(1.5): 214-221.

[54] M. Smola, T. Vandamme, A. Sokolowski, Nanocarriers as Pulmonary Drug Delivery Systems to Treat and to Diagnose Respiratory and Non-Respiratory Diseases. International J ournal of Nanomedicine, 2008, 3(1): 1.

[55] T.J. Kean, P. Lin, A. I.Caplan, et al., MSCs: Delivery Routes and Engraftment, Cell-Targeting Strategies, and Immune Modulation. Stem Cells International, 2013: 2013.

[56] C.J. Cheng, G.T. Tietjen, J.K. Saucier-Sawyer, et al., A Holistic Approach to Targeting Disease with Polymeric Nanoparticles. Nature Reviews Drug Discovery, 2015, 14(4): 239-247.

[57] M.M. Zacchè, S. Srikrishna, L. Cardozo, Novel Targeted Bladder Drug-Delivery Systems: A Review. Research and Reports in U rology, 2015, 7: 169.

[58] K.R. Chowdary, N.K. Rao, K. Malathi, Ethyl Sellulose Microspheres of Glipizide: Characterization, in Vitro and in Vivo Evaluation. Indian J ournal of Pharmaceutical Sciences, 2004, 66(4): 412.

[59] S. Surini, V. Anggriani, E. Anwar, Study of Mucoadhesive Microspheres Based on Pregelatinized. J M ed Sci, 2009, 9: 249-56.

[60] S. Fischer, C. Foreg, P.H. Merkle, et al., Chitosan Coated Plga-Microspheres-A Modular System for Targetting Drug Delivery. European Cells and M aterials, 2004, 7(1).

[61] O.G. Bhusnure, C.A. Shinde, S.B. Gholve, et al., Design, Evaluation and Aseptic Refiner Techniques for Microsphere Formation, (2015).

[62] J.A. Yabagi, I.M. Kimpa, M.N. Muhammad, et al., Structural Transformation of Polystyrene Nanosphere Produce Positive and Negative Resists by Controlled Laser Exposure. Advanced Science Letters, 2017,23(7): 6613-6617?

[63] P.J. Wibawa, M.A. Agam, H. Nur, et al., Changes in Physical Properties and Molecular Structure of Polystyrene Nanospheres Exposed with Solar Flux. In AIP Conference Proceedings, American Institute of Physics, 2011, 1341(1): 54-61.

[64] H. Farzaneh, M.E. Nik, M. Mashreghi, et al., A Study on the Role of Cholesterol and Phosphatidylcholine in Various Features of Liposomal Doxorubicin: From Liposomal Preparation to Therapy. International J ournal of Pharmaceutics, 2018, 551(1-2): 300-308.

[65] A.M. Kadim, A. Dheyaa, A. Jawad, et al., Formation of PVA-PMMA-PAAm Blend with Various content of Dextrin for Drug Delivery Application. Materialstoday: Proceedings, July, 2021.

[66] R. Rathinamoorthy, M. Sumothi, Innovative Application of Nano Fiber. Textile Asia, 2009, 1: 24-27.

[67] A.A. Hamidi, Synthesis Of Pamam Dendrimer As A New Carrier In Cancer Drug Delivery, 2016.

[68] C. Jiang, L. Kuang, M.P. Merkel, et al., Biodegradable Polymeric Microsphere-Based Drug Delivery for Inductive Browning of Fat. F rontiers in Endocrinology, 2015, 6: 169

[69] K.H. Ramteke, V.B. Jadhav, S.N. Dhole, Microspheres: as Carrieres Used for Novel Drug Delivery System. IOSRP HR, 2012, 2(4): 44-48.

[70] M. (Ed.). Mishra, Handbook of Encapsulation and Controlled Release. CRC Press, 2015.

[71] W. Dina, The Study of Actors Affecting the Preparation of Carbon Microspheres by Hydrothermal method, (2016).

[72] X. Yang, L. Chen, B. Han, et al., Preparation of Magnetite and Tumor Dual-Targeting Hollow Polymer Microspheres with PH- Sensitivity for Anticancer DrugCarriers. Polymer, 2010, 51(12): 2533-2539.

[73] H. Tian, Z. Tang, X. Zhuang, et al., Biodegradable synthetic polymers: preparation, functionalization and biomedical application. Progress in Polymer Science, 2012, 37(2): 237-280.

[74] https://www.grandviewresearch.com/industryanalysis/ microspheres-industry, (accessed) 11/10/2018.

[75] A. Kumar, S. Jha, R. Rawal, et al., Mucoadhesive Microspheres for Novel Drug Delivery System: A Review. Am. J. P harmTech Res, 2013, 3:196-213.

[76] A.V. Thummar, C.R. Kyada, R. Kalyanvat, et al., A Review on Mucoadhesive Microspheres as a Novel Drug Delivery System. International J ournal for Pharmaceutical Research Scholars, 2013, 2(2): 188-200.

[77] S. Mukherjee, P. Bandyopadhyay, Magnetic Microspheres: A Latest Approach in Novel Drug Delivery System. J Pharm Sci Innovation, 2012, 26: 21-25.

[78] D. Batra, S. Kakar, R. Singh, et al., Magnetic Microspheres as A Targeted Drug Delivery System: An Overview. J ournal of Drug Delivery Research, 2012, 1(3): 10-17.

[79] M.S. Roslan, K.T. Chaudhary, N. Doylend, et al., Growth of Wall-Controlled MWCNTs by Magnetic Field Assisted arc Discharge Plasma. J ournal of Saudi C hemical Society, 2019, 23(2), 171-181.

[80] A.V. Mayavanshi, S.S. Gajjar, Floating Drug Delivery Systems to Increase Gastric Retention of Drugs: A Review. Research J ournal of Pharmacy and Technology, 2008,1(4): 345-348.

[81] V. Rastogi, S.S. Shukla, R. Singh, et al., Microspheres: A Promising Drug Carrier. J ournal of D rug Delivery and Therapeutics, 2016, 6(3): 18-26.

[82] K.H. Ramteke, V.B. Jadhav, S.N. Dhole, Microspheres: As Carrieres used for Novel Drug Delivery System. losrphr, 2012, 2(4): 44-48.

[83] N.A. Gujarathi, B.R. Rane, J.K. Patel, PH Sensitive Polyelectrolyte Complex of O-Carboxymethyl Chitosan and Poly (Acrylic Acid) Cross-Linked with Calcium for Sustained Delivery of Acid Susceptible Drugs. International J ournal of P harmaceutics, 2012 ,436(1-2): 418-425.

[84] T.M. Allen, P.R. Cullis, Drug Delivery Systems: Entering the Mainstream. Science, 2004, 303(5665): 1818-1822.

[85] J.M. Frechet, Dendrimers and Other Dendritic Macromolecules: From Building Blocks to Functional 
Assemblies in Nanoscience and Nanotechnology. J ournal of Polymer Science Part A: Polymer Chemistry, 2003, 41(23): 3713-3725.

[86] F.M. Muggia, J.D. Hainsworth, S. Jeffers, et al., Phase II study of liposomal doxorubicin in refractory ovarian cancer: antitumor activity and toxicity modification by liposomal encapsulation. J ournal of Clinical Oncology, 1997,15(3): 987-993.

[87] J. Panyam, \&amp; Labhasetwar, V. Biodegradable Nanoparticles for Drug and Gene Delivery to Cells and Tissue. Advanced Drug Delivery Reviews, 2003, 55(3): 329-347.

[88] H. Otsuka, Y. Nagasaki, K. Kataoka, PEGylated Nanoparticles for Biological and Pharmaceutical Applications. Advanced Drug Delivery Reviews, 2003, 55(3): 403-419.

[89] I. Imaz, J. Hernando, D. Ruiz-Molina, et al., MetalOrganic Spheres as Functional Systems for Guest Encapsulation. Angewandte Chemie International Edition, 2009, 48(13): 2325-2329.

[90] M. Oh, C.A. Mirkin, Chemically Tailorable Colloidal Particles from Infinite Coordination Polymers. Nature, 2005, 438(7068): 651-654.

[91] X. Sun, S. Dong, E. Wang, Coordination-induced Formation of Submicrometer-Scale, Monodisperse, Spherical Colloids of Organic-Inorganic Hybrid Materials at Room Temperature. J ournal of the American Chemical Society, 2005, 127(38): 13102-13103.

[92] P. Horcajada, C. Serre, M. Vallet-Regí, et al., MetalOrganic Frameworks as Efficient Materials for Drug
Delivery. Angewandte Chemie, 2006, 118(36): 61206124.

[93] P. Horcajada, C. Serre, G. Maurin, et al., Flexible Porous Metal-Organic Frameworks for A Controlled Drug Delivery. Journal of the American Chemical Society, 2008, 130(21): 6774-6780.

[94] W.J. Rieter, K.M. Pott, K.M. Taylor, et al., Nanoscale Coordination Polymers for Platinum-Based Anticancer Drug Delivery. J ournal of the American Chemical Society, 2008,130(35): 11584-11585.

[95] P. Horcajada, T. Chalati, C. Serre, et al., Porous MetalOrganic-Framework Nanoscale Carriers as a Potential Platform for Drug Delivery and Imaging. Nature Materials, 2010, 9(2):172-178.

[96] I. Imaz, M. Rubio-Martínez, L. García-Fernández, et al., Coordination Polymer Particles as Potential Drug Delivery Systems. Chemical Communications, 2010, 46(26): 4737-4739.

[97] T. Wang, S. Yang, L. Wang, et al., Use of Poly (Amidoamine) Dendrimer for Dentinal Tubule Occlusion: A Preliminary Study. PLoS O ne, 2015, 10(4): e0124735.

Copyright $₫$ Khalid Haneen Abass, Ashraq Mohammed Kadim, Sara Kareem Mohammed, and Mohd Arif Agam. This is an open-access article distributed under the terms of the Creative Commons Attribution License, which permits unrestricted use, distribution, and reproduction in any medium, provided the original author and source are credited. 